\title{
12
}

\section{Transnational Actors and the Diffusion of Social Policies: An Ideational Approach}

\author{
Privilege Haang'andu and Daniel Béland
}

\section{Introduction}

Political scientists have established compelling scholarly evidence that transnational actors (TNAs) such as international organizations (e.g. the World Bank, International Monetary Fund [IMF] and United Nations Educational, Scientific and Cultural Organization [UNESCO]), advocacy networks and epistemic communities can have a significant effect on state policies, on the creation of international norms and on the subsequent diffusion of these norms into domestic practices (Boli and Thomas 1999; Checkel 1997, 2005; Evangelista 1995; Finger and Princen 2013). Predominantly, the transnational policy diffusion literature focuses on

\section{P. Haang'andu}

Johnson-Shoyama Graduate School of Public Policy, University of Saskatchewan, Saskatoon, SK, Canada

D. Béland $(\bowtie)$

McGill Institute for the Study of Canada, McGill University,

Montreal, QC, Canada

e-mail: daniel.beland@mcgill.ca 
the institutionalist approach which holds that political institutions "mediate, filter, and refract the efforts by transnational actors and alliances to influence policies in the various issue-areas" (Risse 2007, 269). According to this hypothesis, political institutions are necessary and sufficient gateways toward successful policy diffusion (for a discussion see Orenstein 2008). The main task of TNAs, therefore, is to seek strategic engagement with domestic, institutionalized political actors and to create among them winning coalitions for the acceptance of new policies and norms. In this chapter, using the example of disability and gender-based policies in SubSaharan Africa (SSA), we suggest that key actors involved in transnational social policy diffusion have overemphasized the role of political institutions. This is the case because TNAs focus their mobilization on the engagement with powerful institutionalized domestic actors to foster successful policy diffusion. However, while institutional factors are important and might be enough to foster success in some policy domains, they fail to explain why some transnational networks operating in the same institutional context succeed, while others fail (Keck and Sikkink 1998). As Risse $(2007,270)$ argues, the political-institutional approach to transnational mobilization stresses "formal aspects of political and social institutions rather than the substantive content of ideas and norms embedded in them". We selected disability and gender policy domains because of two reasons: first, because the study is about the success and failure of policy diffusion, we needed two policy areas with contrasting success rates. Disability and gender policies, despite facing significantly similar social barriers, show contrasting policy diffusion success rates in southern Africa. Moreover, we aimed at comparing two policy areas whose appearance on the transnational scene is not punctuated by large temporal gaps. International issues of advocacy, disability, and gender became central at about the same time (2000 for Millennium Development Goals [MDGs] with MDG 8 specifying gender equality and 2006 for the Convention on the Rights of Persons with Disabilities [CRPD]). This situation makes it easier to compare the simultaneous fate of disability and gender policies in SSA. Second, both policy areas face similar ideational challenges (e.g. cultural-cognitive biases, stereotypes and marginalization).

In this chapter, therefore, we develop an alternative approach to transnational mobilization built on ideational factors (e.g. cultural contexts, 
identities, norms, symbols and language) to explain the variation of TNA success with policy diffusion. Simultaneously, we lay out ideational factors shaping social policy diffusion in SSA and demonstrate the necessity of an ideational approach.

Our theoretical approach, contrary to the predominantly supplydriven institutionalist approach, is driven by symmetrical interactions between the supply of policy ideas and the demand for these ideas in the policy diffusion process. Our approach, anchored in the role of ideas in policy diffusion, claims that policy diffusion is significantly impacted by local ideational factors beyond the reach of formal political institutions. As both supply and demand matter for policy diffusion, we argue that the bricolage and translation of ideas are important for achieving successful policy diffusion. While translation is about adapting foreign ideas to a particular normative or institutional setting, so that they can blend (Clarke et al. 2015), bricolage is about combining different pre-existing ideas and institutional components to create something new (Campbell 2004).

\section{An Ideational Framework}

\section{Bricolage, Translation and Policy Transfer}

To conceptualize a policy diffusion approach that goes beyond the dominant political-institutional perspective discussed above, we propose an ideational approach (Parsons 2007) that finds expression by way of bricolage and translation (Campbell 2004). This new framework stresses the importance of ideational persuasion (see Fig. 12.1) for transnational actors seeking to bring about domestic policy change while minimizing the risk of resistance on the part of domestic actors (elected officials and the electorate).

To understand ideational processes, we can turn to Parsons (2007) who couches a typology for explaining political behavior according to two logics: the logic of position (structural and institutional) and the logic of interpretation (psychological and ideational). The logic of 


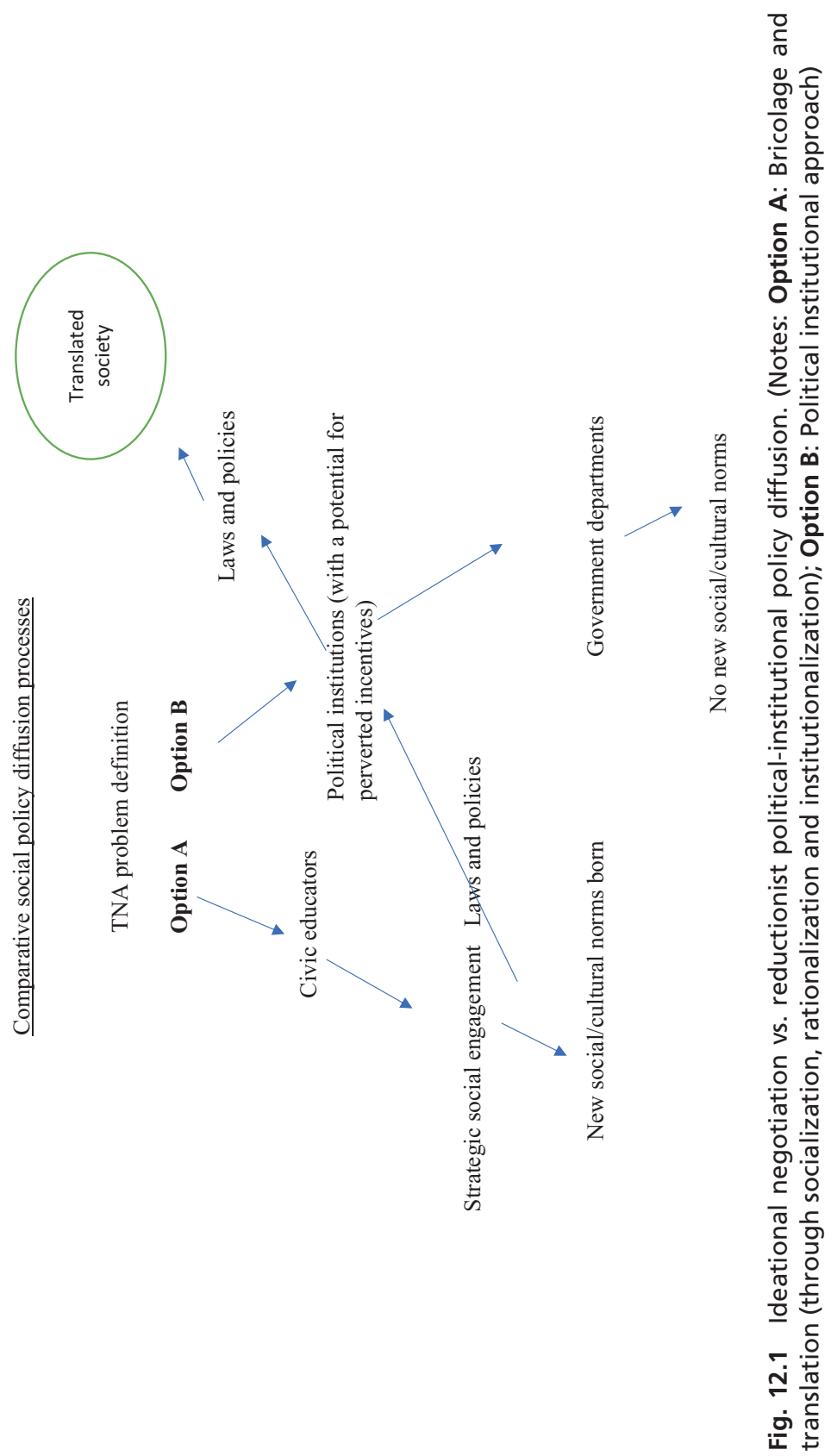


position "explains by detailing the landscape around someone to show how an obstacle course of material or man-made constraints and incentives channels her to certain actions" (Parsons 2007, 13). On the other hand, the logic of interpretation "explains by showing that someone arrives at an action only through one interpretation of what is possible and/or desirable" (Parsons 2007, 13). According to Parsons, therefore, explanations of political behavior can be classified as one out of four types contained in the two logics above: structural, institutional, psychological and ideational. According to the logic of interpretation, the difference between ideational and psychological forces is stark: the former are historically constructed and the latter are about hard-wired cognitive processes. What we abstract from Parsons is the concept of ideational explanations. For Parsons $(2002,48)$, ideas — which give ideational explanations of their name-are "claims about descriptions of the world, causal relationships, or the normative legitimacy of certain actions". Ideas are constructive interpretative lenses through which actors make sense of their material, social and political environment.

Parsons argues that ideational claims are particularistic in that they rely on the consequences of prior contingent actions, and that they trace the causes of action to some historically constructed practices, norms and ideas through which individuals interpret the world. However, as Parsons (2007, 97-98) notes, "people may invent a stunning range of beliefs and practices, but they do not quite do so in infinitely flexible ways". Ideational foundations, though amenable to alternative persuasion through framing, foster stable sociological identities. As Trebilcock $(2014,39)$ argues, because societies' ideational positions are relatively stable over time, they "serve as an important foundation to which policy proposals must generally be tied, in one form or another, in order to gain popular acceptance". The fact that these beliefs are to some extent flexible makes it important to consider translating policy proposals for local appeal to a sense of normative fairness and appropriateness (see Trebilcock 2014). It is this need for framing in policy diffusion that necessitates the next part of our ideational framework.

The concepts of bricolage and translation at the core of our ideational framework are derived from Campbell's work on institutional change. In his analysis of how various ideas can shape institutional change, Campbell 
(2004) discusses translation and bricolage, two mechanisms according to which different ideas and institutional elements are combined and reframed in particular institutional contexts. On the one hand, Campbell argues that when new ideas are introduced into a new cultural and institutional context through diffusion processes, these ideas are typically translated into local practice to varying degrees. From this perspective, translation is about adapting foreign ideas to a particular normative or institutional setting so that they can blend in (Clarke et al. 2015). Bricolage, on the other hand, is about combining different pre-existing ideas and institutional components to create something new (Campbell 2004). In other words, bricolage relates to the capacity of actors to create something new out of the ideational and institutional legacies that already exist in their environment (Campbell 2004; Carstensen 2011).

Bricolage and translation in policy diffusion in SSA are necessary to enhance policy diffusion. Empirically, because of its unique historical, cultural, economic, religious and political experiences that collectively shape social and political existence in a unique way, the SSA social context does not render itself adequately amenable to the Western-centric legislative approach without addressing preliminary contextual and cultural factors. As illustrated, existing models of concentrating on legislative procedures and targeting political institutions for envisioned transformation have proved futile and even counterproductive, demanding alternative approaches. In practice, social norms cannot change overnight through the prescription of legislation. Unfortunately, as Grech $(2011,93)$ argues, the Global South has since colonial times been "construed as a blank slate, waiting for outside intervention". Social norms, likable or not, constitute identities and meanings that cannot be supplanted through legislation alone. As Scott (2005) argues, cultural knowledge is an essential component of policy design and meaning.

Contrary to the institutional approach, the translation and bricolage of ideas offer a more viable and tenacious promise as a mechanism for cultural and ideological policy change in the Global South. This change works both through strategic social agents at the societal level and, although later, through political institutions. While political institutions are often susceptible to political and economic manipulation by the powerful, they are socially ill-positioned to drive such bottom-up ideational 
innovation. Figure 12.1 illustrates the difference between the two diffusion approaches. In the words of Miljan $(2012,5)$, "a program, law, or regulation hardly ever 'solves' a problem in the sense of eliminating the conditions that inspired demands for action. When a problem does disappear, the reason often has less to do with government action than with changing societal conditions_-including the emergence of new problems that push old ones below the surface of public consciousness".

Without any ideational fix, therefore, law enforcement is powerless. Political actors, often perceived as elitists, are ineffective with engendering changes of norms embedded in existing cultural and religious identities. In their place, we propose the deployment of strategic social actors whom we call civic educators as translators and bricoleurs (i.e. ideational entrepreneurs): traditional leaders, religious leaders, teachers, issue-based advocates, journalists and other social entrepreneurs. It is among communities, families, social groups and associations that ideological frames are constituted and sustained. In her argument about when a subject ripens for public attention, Miljan (2012) demonstrates how, in industrialized democracies, a change of cultural attitudes preceded the political agenda to address unequal social conditions of males and females, for example equal pay for equal work. It was cultural change, not legislation per se, that necessitated the revolution for gender equality. Subsequent legislative efforts supported the ideational transformation that was a result of a policy discourse.

Civic educators are strategically positioned to reinforce or alter social beliefs, to challenge epistemological positions and to help re-align norms, values and "truths". Simply put, they are well-positioned to actively promote ideational transformation. For example, in the Global South transnational actors can work through community players such as community leaders and heads of religious organizations incorporating endogenous norms, values and ideas. This is more impactful in reversing trends such as child marriage and domestic violence.

A potential entry point for championing ideational and policy influence in the Global South is an appeal to the pre-existing communitarian sense of solidarity, family care and social cohesion. For instance, Grech (2011) acknowledges the importance of family ties for offering solidarity 
and social support in the Global South. Communal solidarity provides a profound opportunity for social policy development in the region.

\section{Supply and Demand in Policy Diffusion}

While some scholars believe that political institutions are necessary and sufficient gateways toward successful policy diffusion (Risse 2007), others see a stronger symbiosis between formal rules/laws that constrain and shape social action and the embedded informal norms that legitimate those formal rules (Campbell 2004; North 1994; Scott 2005). The latter ideational approach stresses that institutional change does not simply mean a change of policy instruments, but, most profoundly, a change of norms that underpin the objectives of these instruments and provide them with legitimacy.

We argue that this constructivist and ideational approach, which has two implications for policy diffusion, suggests a two-faceted policy diffusion process: supply and demand. Before explaining this in greater detail, we are going to deal with the implications of our constructivist and ideational approach. First, because policies — as formal rules and preceptsare institutional realities, their change must seek to alter not just the instrumental aspects represented by formal rules but also the normative aspects including social expectations, customs and belief systems. These social factors, which Parsons (2007) calls ideational factors, matter significantly for policy diffusion because every society is defined by its own sets of persistent cultural ideas. These ideas define societies, and they create and establish social interests that societies live by and would not willingly sacrifice because policy instruments have changed.

Without ideational strategies that socialize and rationalize the new precepts, no punitive law would easily engender any change of core social norms. This, therefore, raises an important issue about framing in policy processes. As Baumgartner and Jones $(1991,1046)$ demonstrate in what they call "policy imaging", the framing of policy ideas is crucial not only for the justification of new policies but also for the legitimation of alternative world views. 
Second, the degree of policy change is only as profound as the policy proposers' scope of engagement with diverse social actors who legitimate a given political idea. If Hall's (1993) third level of policy change (paradigm shift) is desired, context-specific ideas that determine social objectives and goals according to which institutions and policies are designed must be taken into account. To do this, any meaningful activism should be based on a coherent and contextual understanding of institutions, their rules and operations. The assumption that institutions have a universal character often leads to the pitfall that they could resolve all social problems regardless of cultural and normative circumstances (Haang'andu 2018). In this case, social scientists have shown that the logic according to which the change of formal rules (or policy instruments) is sufficient for changing human behavior is flawed. Douglas North (1994), for example, argues that while it is easy to change formal rules overnight, informal norms, which are the anchor for belief, identity, knowledge and behavior, usually change only gradually. The logic here is that institutions are birthed through social interactions and that they are often a representation of the people's cultural-cognitive values and informal beliefs (see also Campbell 2004, 1-9). Institutions and their enforcement build on and reinforce informal norms and beliefs. They create reciprocal expectations and standards because of repeated human behavior and in response to them. In other words, they create a culture.

The preceding discussion leads to the conclusion that transnational policy diffusion should be mindful of two important components of diffusion: the supply and the demand components (see Fig. 12.2). These two components have implications for understanding power relations in policy diffusion and for determining the success and failure of policy diffusion. The supply side simply means that a policy entrepreneur identifies a situation (problematic or not) requiring a policy response and proposes a solution. For example, the observation that socio-economic and political benefits are unequally distributed among men and women has led to the emergence of feminist solutions.

However, supplying policy ideas should be balanced with the demand side. The demand side has two components: inactive demand and active demand. The inactive demand side is primarily guided by what Campbell $(2004,94)$ refers to as "public sentiments". It means that if an outsider 


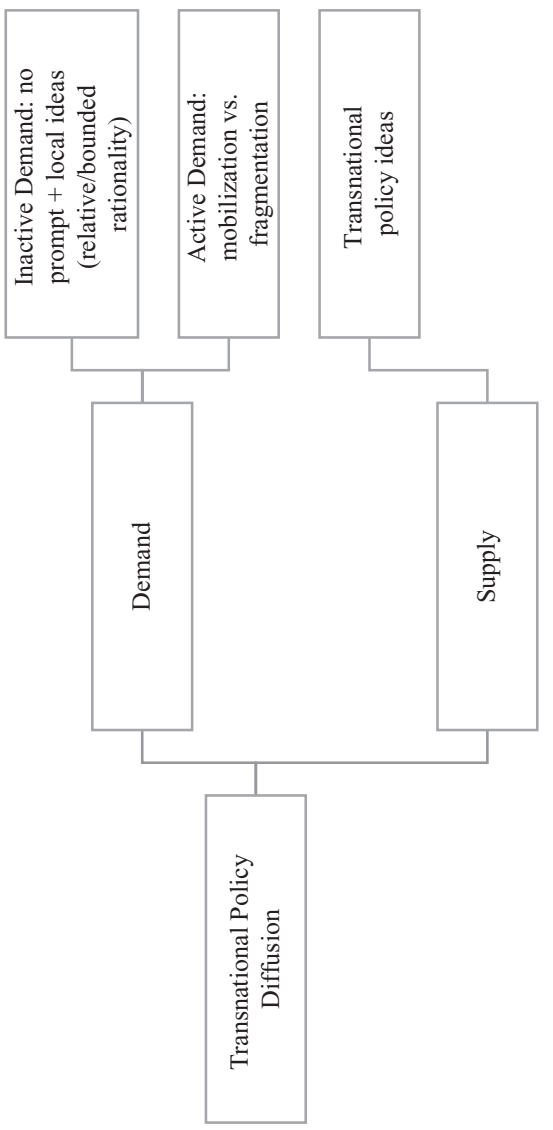

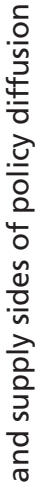

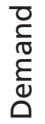


attempts to change them, public normative resistance is imminent, potentially seeing such attempts as ideological and cultural intrusion. From this perspective, the inactive demand is where a given society does not actively seek change to its status quo, but an outside policy proposer seeks to initiate change based on perceptions of a situation the outside actor sees as problematic. The policy proposer must prove through a compelling indicator that there is need for a change of the status quo. As Kingdon (2003, 93) argues, "constructing an indicator and getting others to agree to its worth become major preoccupations of those pressing for policy change". For instance, society A could have traditional gender relations it does not see as problematic, although actor B (a TNA) considers them a problem. On the whole, transnational actors and policy proposers see problems beyond their jurisdictions and promote solutions, assuming or believing that a perceived problem borders on a universal principle or that their proposed solution is responsive to their diagnostic (see Shriwise, Chap. 2, this volume, but also Chinyoka and Ulriksen, Chap. 10, this volume).

The demand side also has an active component where a given policy community actively seeks policy solutions for a perceived problem. Still, this demand for policy solutions could be either endogenously or exogenously created. Moreover, the interactions of the supply and demand sides of policy diffusion inherently entail power relations, whether symmetrical or asymmetrical. For policy diffusion to be legitimate, policy entrepreneurs must be aware of the potential for ideational domination. The next section specifies why and how power matters in policy diffusion and how, if not properly managed, it could result in ideational asymmetries and policy impositions.

\section{Power and Policy Diffusion: Implications for Political and Ideational Asymmetries}

Although international organizations often present transnational policy ideas and norms as being neutral, universal and disinterested, political scientists have demonstrated that transnational policy diffusion is characterized by power contestations (Waltz 2000; Shriwise, Chap. 2, this volume). A perspective on the idea of power that has sparked academic 
controversy is the one by Steven Lukes (2004). Lukes holds a neo-Marxist view according to which power is relational and asymmetrical. It is power over others. According to him, power is the ideological capacity to misleadingly shape the preferences of other actors, in order of reinforcing their domination (Béland 2010). Contrary to Lukes' conception of power as "power over", Morriss $(2006,126)$ argues that "our primary understanding of power is as "power-to" and that "it follows from this that 'power' is best thought of as the ability to effect outcomes, not the ability to affect others". Understanding the conceptual distinction between Lukes' "power over" and "power to", which refers to the capacity to shape outcomes (Morriss 2006), is crucial for our understanding of transnational policy diffusion.

While transnational players are autonomous actors, their policy ideas are seldom those without the backing of powerful countries that finance their operations (see Shriwise, Chap. 2, this volume; Mioni and Petersen, Chap. 3, this volume). While many times TNAs have openly used their control over these institutions to manipulate global political outcomes (which Lukes suggests as "power over"), transnational policy is almost always characterized by power asymmetries. Although transnational policy diffusion, as Hall (1993) puts it, is always about "powering" and "puzzling", achieving policy outcomes through the manipulation of formal political institutions, particularly on matters socially and culturally entrenched, is seldom a viable way of diffusing policy. In the case of disability policy, the failure has more to do with assumptions of Westerncentric norms that overshadow the predominance of local cultural ideas in influencing collective identities that could stifle policy diffusion. As Campbell (2004) suggests, policy change should address not only cognitive but also normative ideas, bearing in mind the background and foreground variables affecting the acceptability of policy change. 


\section{Case Study: Transnational Policy Diffusion in SSA}

A couple of key points emerge from the preceding discussion that point to the inadequacy of the political-institutional framework and stress the need for our alternative ideational approach. To illustrate the usefulness of this approach, we apply it to transnational disability policy diffusion in SSA, which we then compare with diffusion in the field of gender equality. By way of these factors outlined below as part of our general framework, we demonstrate how the policy diffusion process could be enhanced.

The reason why we selected disability policy to illustrate the benefit of our approach is twofold. First, it is a field in which the limits of the traditional-institutionalist approach to social policy diffusion are easy to identify (Haang'andu 2019). Second, it is a field where the supply side to social policy diffusion has been overemphasized without paying attention to the demand factors. Disability literature is dominated by a strong Western-centric institutionalist approach that has effectively marginalized the role of local ideas in building strong social policy responses to disability. As some scholars have acknowledged (e.g. Devlieger 1999; Grech 2011; Meekosha 2011; Soldatic and Grech 2014), despite accounting for over $80 \%$ of persons with disabilities worldwide, the Global South remains at the periphery of "development policy, research and programs, and virtually excluded from the Western-centric disability studies" (Grech 2011, 87). In addition, they argue that the "universalization" of Westernfounded disability paradigms, which in our model is denoted by the supply component, has negative impacts, especially on the Global South where experiences of disability are profoundly different.

What we see in SSA in the two policy domains under consideration is a contrast between how gender policy entrepreneurs designed a very wellorchestrated diffusion approach addressing both the demand and the supply sides, while the disability policy entrepreneurs stagnated at the supply side, weakly addressing the demand side. Where the supply side is emphasized, especially if policy ideas border on power relations, policy change evokes ideational asymmetries, something Grech (2015) calls 
epistemic violence. Often, this leads to ideational acquiescence and conquest. In Haang'andu's (2019) study, disability policy participants agreed that cultural barriers such as beliefs in ancestral curses, myths about the causes of disability and religious beliefs were strong, but also that organizations of persons with disability (PDOs) are fragmented. This means that the two demand components (active and inactive) of the disability policy framework are unviable. While the inactive component of the demand side of gender policy was equally non-viable (by being ideationally guarded), its active demand component facilitated dynamic changes to the two demand ends (active and inactive) to increase cultural receptiveness at the supply end. This process is key to the legitimation of policy change.

Moreover, in SSA, disability policy diffusion is an understudied topic that requires a more systematic approach, something we offer in the following sub-sections. In these sections, where useful, we compare policy diffusion in the field of disability with the situation prevailing in the area of gender equality. We do so because gender equality as an issue provides a revealing contrast with disability policy as far as the study of diffusion patterns is concerned. First, because the chapter is about the success and failure of policy diffusion, we needed two policy areas with contrasting success rates. Moreover, we selected two policy areas whose appearance on the transnational scene is not separated by a large time difference. These two became prominent on the transnational scene at about the same time, the year 2000 for gender, as one of the eight United Nations' MDGs, and the year 2006 for the CRPD. The fact that they have had fairly an equal time for implementation legitimates a comparison. Second, both policy areas face similar ideational challenges (e.g. cultural-cognitive biases, stereotypes and marginalization). Our interest here is not why gender equality and not disability has made it among the core MDGs. Instead, our goal is to compare policy processes that transnational actors and their domestic allies have undertaken to reverse women's marginalization and those that transnational actors and their allies have deployed the past two decades in disability advocacy. How did transnational actors transcend the political processes to attend to sociological causes such as child marriages, gender-based spousal violence, sexual cleansing/HIV and female genital mutilation? These are entrenched social/cultural issues 
that formal political processes alone could not resolve. Considering that transnational disability actors face similar ideational challenges, how could gender policy diffusion processes shed light on disability policy diffusion?

\section{Individual Rights, Communitarianism and Policy Diffusion: Contesting Universality}

In a statement disputing the assumed universality of a Eurocentric disability discourse, Grech $(2015,11)$ writes:

Despite the attempts by a handful of materialist disability theorists to engage with the so-called 'majority world' [...], it becomes immediately clear that these efforts appear to be limited to writing in, or making the Global South fit into their dominant perspectives as opposed to learning about this complex and hybrid space in its own right [...]. For some, the objective may well be the transfer and exportation of discourse, in this case the strong social model of disability to everyone, everywhere, with the objective of reinforcing its universality as a global narrative and perhaps reasserting the power of those generating and selling it.

Indeed, the current transnational disability discourse is imbued in Western knowledge and ideological, theoretical, cultural and historical assumptions (Grech 2015), with little sensitivity to different ideational local contexts. One such method is the rights-based approach to disability that seeks to valorize the individual against the collective. One of the biggest challenges with transnational human rights-oriented policy diffusion in Africa is the overlooking of historically entrenched collective identities which are essentially non-individualistic. Many African scholars have written on the Bantu philosophy of Ubuntu (e.g. Christians 2004; Mji et al. 2011; Wiredu 2008) that so profoundly characterizes the Bantu people of SSA. The term ubuntu is common among many Bantu languages across the continent and it translates as "humanity for others" (Christians 2004, 241). In the Zulu language, for example, ubuntu derives from a maxim umuntu ngumuntu ngabantu, which translates as "a person is a person through other persons" (Christians 2004, 241; see also 
Mji et al. 2011) or I am because we are. As Christians (2004, 241) explains, ubuntu "means that a person depends on personal relations with others to exercise, develop and fulfil those capacities that make one a person [...]. Personhood comes as a gift from other persons". Central to the concept of ubuntu is the understanding that human beings are intrinsically social beings and that their dignity is integrated in rationality and morality (Christians 2004).

Contrary to this approach by disability advocates, in his comparative study on disability and gender policy advocates in Malawi and Zambia, Haang'andu (2019) finds that while the promotion of gender equality was central to the objectives of feminist TNAs, persuading endogenous ideational factors was equally important. The most notable intermediary TNAs and local organizations engaged with transforming social norms were traditional leaders, teachers, religious leaders and husbands. Haang'andu (2019) shows that TNAs and their partners used framing techniques to persuade ideational, cultural and knowledge leaders toward alternative frames of gender relations. This helped, prior to the attainment of effective institutional frameworks, with altering entrenched societal ideas maintained in the context of belief systems and practices that placed women at the periphery.

The comparison demonstrates that cultural identity, unlike Western individualism, is more of involuntary acquiescence. People are born into a culture they can individually hardly control. Individuality versus communitarian comparatives has serious implications for the applicability of legal and judicial frameworks that stress individual rights against common values. In entrenched Western democratic societies, where individual liberties and freedoms are central to civilization, court systems and litigation are effective. In these societies, judicial processes through institutionalized courts are strong and binding for all parties involved. The institutional court system as we know it today, as a pinnacle of individual emancipation, is an abstraction of the Western civilization. The judiciary, as an arm of government, is a colonial inheritance. Like other colonial institutions of governance in Africa, the concept of the Western-centric judiciary is still struggling to entrench itself in African political cultures.

This has created two problems. First, the sense of communal solidarity, collective responsibility and shame is more binding than the doctrine of 
individual exoneration through judicial victories (Haang'andu 2018). Second, judicial impartiality in Africa remains a significant problem. Some scholars have argued that judicial systems in developing countries are generally weak (Besley and Persson 2014). In a robust study on the adjudication of electoral disputes in SSA, O'Brien Kaaba (2015) documents the challenges of judicial neutrality throughout Sub-Saharan Africa. In all SSA countries, constitutions allow presidents to appoint judges, often without tenure of office, leaving the judges' security of office to the caprices of politicians: the result has been that judges are often politically pliable. In the rare cases when judges exhibit independence and rule against government officials, their verdicts are ignored, publicly ridiculed and sometimes judges are removed (Haang'andu and Béland 2019).

The foregoing two points have far-reaching implications for policy diffusion in SSA, when we bring the example of gender equality to the fore as a comparative device. First, women and persons with disabilities, like everybody else, hold collective purposes more than individual "rights", contrasting the experience of Western civilizations (see also Grech 2011). These social ties shape the experience of gender relations and the disability experience in a way that creates unique opportunities and challenges for policy intervention. Our experience of research in Malawi and Zambia shows that women are overly reticent about gender-based abuses because of this cultural-blanket. In many cases when reports are filed, they are often withdrawn, and cases can be withdrawn to preserve collective "integrity". Second, although courts have mostly acted efficiently in case of gender-related violations where they have been allowed to, the implication of weak judicial systems for the transnationalization of disability norms is that there is no predictability as to whether court systems would act as credible remediation for disability causes. In SSA, where government executives frequently influence the judiciary or defy judicial rulings, it is difficult to imagine that courts would - contrary to Vanhala's (2010) arguments for the relevance of courts in Canada and in the United Kingdom—be credible means to champion disability "rights", especially 
when judicial outcomes have punitive financial implications on arms of government (Haang'andu 2018). ${ }^{1}$

\section{Ethnolinguistic Fractionalization and Policy Diffusion}

One of the conspicuous characteristics of many SSA societies is cultural heterogeneity. Political scientists have theorized about the implications of ethnolinguistic fractionalization when it comes to the building of institutions. One of the arguments brought forward is that ethnolinguistic fractionalization complicates institution-building and policy change (Besley and Persson 2014; Mauro 1998). In an ethnolinguistically fractionalized society, the diversity of cultural ideas makes it difficult to impose a homogenous policy across the country. The assumption that gender equality norms, disability knowledge and policy ideologies founded in one part of the world would seamlessly localize in ethnolinguistically fractionalized SSA is problematic (Haang'andu 2018).

Because of their ethnolinguistic fractionalization, many SSA societies are ideationally and culturally fragmented and require more complex strategies of disability and gender policy response than the Western universalistic agenda. The existential realities of persons with disabilities in SSA are, in terms of both challenges and opportunities, uniquely shaped by local ideational factors that might not be amenable to a universal policy prescription. Building universal disability regimes that command voluntary multi-ethnic acceptance is much more complex than the transnationalization of unquestioned Western-based ideologies (Haang'andu 2018).

In his study on Malawi and Zambia, Haang'andu (2019) finds that an important obstacle to disability policy diffusion in SSA is the lack of TNAs and their partners' strategic engagement with grassroots actors to initiate a critical ideational shift that both backs the change in formal laws and rules and, at the same time, puts pressure on social factors sustaining existing frames about disability. Gender activists and their TNA

\footnotetext{
${ }^{1}$ This is a good project for future investigation. There is the need to study how effective courts have been in adjudication disability and gender cases in SSA. It is not the priority of this research to delve into such details.
} 
partners have applied this model. While fighting for legislative reform (laws, budget inclusiveness, increased electoral participation, more representation in appointed senior government positions, etc.), they took to the grassroots to sell and rationalize alternative ideational images and frames about male-female relations. Gender activists and disability activists in SSA face similar social obstacles: inhibitive social and religious belief systems, stereotypes, contested status and so on. Like gender TNAs and advocates acknowledged in Haang'andu (2019), framing requires skillful engagement with oppositional and often-entrenched cultural images that people could be defensive about. It also requires persuasion rather than conquest.

As Grech $(2011,89)$ aptly observes, when disability knowledge and policy is grounded on Western-centric ideologies and experiences, "it implies that it is theoretically ill-equipped to deal with majority world views and the nuances of majority world contexts (historical, social, economic and political)". Given the cultural-cognitive embeddedness of both gender relations and disability in SSA countries, it is important to understand that whatever policy interventions are made, they must confront the harsh reality of the deep ideational understanding of gender relations and disability (Haang'andu 2018). As such, activist efforts in these contexts need to employ effective discursive (or rationalization) frames toward the public through carefully selected strategic intermediaries (i.e. civic educators) to convince them that reform is necessary (Kingdon 2003). Like any other societies, SSA societies have unique cultural idiosyncrasies that are difficult to change overnight. Many countries in SSA have a strong adherence to social collectivism and family ties (for disability in the Global South in general, see Clare Barker and Stuart Murray 2010; Grech 2011).

In his research on Zambia, Haang'andu (2019) found that over $90 \%$ of domestic child sexual defilement cases were perpetrated by close relatives and not by unknown strangers. He found that the greatest obstacle to fighting sexual violence and rape of women and young girls is not the lack of punitive laws but that families decide to protect violators to prevent "family shame". In this example, despite the existence of punitive legislative provisions, social norms, beliefs and practices (which Elinor Ostrom (2014) refers to as evolutionary and cultural social norms that 
create reciprocal expectations) stifle the prosecutorial prospects. While most of the cases remain unreported due to these social justifications, in some instances victims report violations but withdraw complaints yielding to family and societal pressure, to avoid "family shame". Often, families prefer secret domestic dispute settlement to judicial proceedings that could potentially result in the arrest and persecution of one of their kith and kin, sometimes the family breadwinner. Haangandu (2019) found that familial protectionist tendencies exacerbate the sexual abuse of girls and women. Women with disabilities, whom some African societies believe to possess spiritual powers to cure sexually transmitted diseases, are at a higher risk.

How should activists confront such socially entrenched barriers? Any gender or disability activism that insists on the supremacy of individual rights is not only incongruent to the experience of gender relations or of persons with disabilities in this context, but it is counterproductive. Given all the historically created and sustained social expectations, it is unlikely that women or individuals with disabilities-so embedded within this social fabric-would seek litigious measures against their immediate family, community or ethnic group for perceived violations.

Where powerful policy proposers use their economic incentives to manipulate and obtain compliance, 'power over' could secure a change of policy instruments but not of social identities, norms and practices. With transnational actors playing dominant roles in financing development policies in both gender and disability in SSA, these countries are faced with the challenge of "puzzling and powering". Presented with treaties at the international level, disregarding their capacity and desire to implement the provisions, these countries' dispositions to accept policy proposals are constantly determined by the "powering" dynamics of appeasement and the fear of retributions. For example, in September 2018, the British Government, along with the Swedish, Irish and Finnish governments, suspended donor aid to Zambia after the Zambian government had misappropriated over $\$ 4$ million meant for social cash transfer programs for poor people and people with disabilities. Therefore, the split of control between transnational actors who wield financial power and state actors who organize their local systems threatens the viability of real paradigmatic change in policy diffusion in general. Although there are no 
absolute solutions to this problem, aligning both actors' goals through ideational bricolage and translation provides a strong remedy. Bricolage and translation offer an ideational approach that both presents legitimacy for locals and satisfies the universalistic aspirations of the TNAs.

\section{Bricolage and Translation of Ideas}

At first, to make disability policy pathways that might break up the sociological and cultural foundations of African societies, disability activism in SSA should be informed by the endogenous understanding and experience of society. In other words, both translation and bricolage should be cognizant of endogeneity. Using bricolage and translation, we can begin to build an Afrocentric disability activist paradigm whose foundations derive from African cultures themselves. To start off the bricolage process, we acknowledge that typically African societies are characterized by a culture of reciprocity, dignity, humanity and mutuality in the interest of building and maintaining communities with justice and communal caring (Gyekye 1997). Bricolage entails the incorporation of these preexisting endogenous attributes into policy responses. For example, the institutionalist introduction of designated homes for persons with disabilities, such as mental health clinics and hospices, negates the entrenched community predisposition of caring for "disadvantaged" members of society. A welfare system created through bricolage that seeks to address the needs of persons with disabilities in such a context would be responsive to pre-existing societal attributions and combine them with other policy elements. The abovementioned African philosophies present profound opportunities for the reconceptualization of a context-responsive model of disability activism within the SSA context. Because it is among communities, families and sociological groups and associations that disability frames are constituted and sustained, it is also from among them that ideational spinners for conceptual shifts should emerge. The preoccupation of transnational activists with political processes of disability policy change and rights promotion misses this point.

Unlike bricolage that maximizes pre-existing attributes for anchoring policy change, translation is predominantly supply-driven. Because the 
supply aspect of policy ideas could easily be perceived as an imposition or as the supplanting of a status quo and, therefore, trigger oppositional public sentiments, it requires a careful framing and translation of ideas. While political institutions play a significant role in the policy process, they are ill-positioned to mediate the framing and translation of supplydriven ideas to how to reconcile them with entrenched non-formal cultural-cognitive beliefs and attitudes. Instead, it is civic educators (traditional leaders, religious leaders, community leaders, teachers, etc.) that are best placed to be ideational entrepreneurs. Civic educators, particularly in the African context, are strategically positioned to reinforce or alter social beliefs, to challenge epistemological positions and to help realign norms and values. The pitfall of the Western-centric disability activism is both its assumed universalistic disability knowledge paradigm and its methodological approach that, despite ideational variation, seeks an institutional expansion of individual rights in a deeply communitarian society.

To amplify the mechanisms of policy translation, let us consider a concrete gender-related example that enriches our comparative analysis of the two policy domains under consideration. In the early 2000s, transnational activists sponsored and supported a vibrant gender activism in Africa that resulted in a plethora of women-led activist organizations (Haang'andu 2018). At inception, there was a strong focus on criminalizing certain social ills; for example, spouse inheritance, sexual cleansing, gender-based violence, the marriage of underage girls and so on. Certain male-female interactions that are commonly taken for granted in African societies came under scrutiny, and many were deemed violations of women's rights. Although these efforts were obviously important for trying to deter the abuse of women and for enhancing women's rights, transnational and domestic organizations that worked to reverse these trends in many African countries eventually realized, after decades of working through legislative avenues of government with little success, that working through community leaders such as chiefs and heads of religious organizations, incorporating endogenous norms, values and ideas, was more impactful for reversing the trends. In fact, in some cases, simply enforcing the law was counterproductive because societies became more reticent about the occurrences of some of these ills. For example, the 
Zambia National Women's Lobby, the largest women's movement in Zambia with a wide regional range in southern Africa, acknowledged during an interview that they had learned that they needed to desist from framing their messages as "promoting women's rights" during their campaigns to make an impact on the heavily patriarchal Zambian society (Haang'andu 2019). The justification for using alternative frames was that the patriarchal Zambian society would be aversive to such language and, therefore, resistant to transformation. Yet, the result of its advocacy was the attainment of communities that developed a new sense of respect for women and their contribution to society and the condemnation of the physical and emotional abuse of women in marriage as well as the increased appreciation of education for girls. The organization also reiterated the importance of working through informal structures as opposed to concentrating on legislation. This point was reiterated by a senior Zambian government official during an interview: "we do not want to be a police state. We need transformation of attitudes and not mere forced compliance to legislation".

This illustration serves to stress a couple of points. First, understanding ideational and cultural contexts is fundamental for activism on sociologically entrenched phenomena like gender and disability. Assumptions of universal categories only serve for stifling progress in ideational transformations. To maximize their impact, transnational activists therefore need to avoid assuming that a knowledge paradigm generated in one culturalcognitive context meets universal resonance and, instead, seek niches for bricolage and identify effective intermediaries for translation.

Second, while the strengthening of institutions is important and in fact essential for a sustained policy, political institutions are not always the best entry points for socially effective policy change. The above illustration shows that informal community structures could be more impactful with proliferating alternative worldviews and with reversing historical frames about taken-for-granted social experiences. In African settings, elected leaders, frequently construed as "seasonal visitors" who show up near election time, are often less trusted than community and religious leaders when it comes to norms-related issues. Traditional ethnic leaders and religious leaders wield both political and ideational authority over communities. They are influential normative spinners 
and can function as strategic ideational entrepreneurs for new knowledge shifts. They are better placed socially to be carriers of new disability frames and to be agents of ideational change than conventional political institutions.

\section{Conclusion}

The contribution our ideational approach makes to transnational policy diffusion is threefold. First, using the examples of disability and gender social policies, it strives to explain the limitations of the institutionalist approach to transnational policy. More broadly, focusing on both, the supply and the demand sides, the framework strives to determe the circumstances under which TNAs succeed and/or fail to diffuse transnational norms in an ideationally charged socio-political environment. Second, the framework abstracts the implications of underlying power factors in policy diffusion. Here we propound the ideational and policy implications of a policy exchange situation that is characterized by power asymmetries. Third, our framework bridges complex public policy concepts to devise an explanatory framework for social policy diffusion that could be applied to many policy situations. Through Parsons' (2007) notion of ideational explanations, we have abstracted ideational components of SSA societies and how they define these societies' identities. Using Campbell's (2004) concepts of bricolage and translation, we devise a comprehensive and inclusive approach to policy diffusion that institutions could adopt to strengthen their own chances of success in diffusing social policies.

This constructivist argument we advance for disability policy diffusion based on ideational considerations, and against a purely positivist political-institutional approach, adds a novel approach both to disability literature and to transnational policy diffusion thought. The approach stands in contrast to the dominant and often-unquestioned politicalinstitutional paradigm of the transnationalization of the disability discourse which, if anything, overlooks context-specific cultural and ideational factors by assuming the universality of Western geopolitical ideologies, norms and interests. Through a strong emphasis on the 
importance of ideas, social meanings, as well as historical and cultural identities in disability policy design and implementation, this study contributes to constructivist theory-building in public policy research.

While this chapter, to a large extent, breaks new ground in social policy diffusion, the framework could benefit from further research work. First, future research could focus on concrete comparative cases drawn from SSA countries while representing internal political and cultural variations (e.g. colonial legacies), to find out: (1) if political historicity has any influence on policy diffusion behavior by TNA; and (2) if colonial legacies have significance for local societies' disposition to exogenous influence. Second, future research could compare what the dynamics of policy diffusion are between more ethnically heterogeneous societies and those less ethnolinguistically fractionalized. Here, it would be useful to investigate whether less fractionalized societies are more or less cohered to social identities such as culture, belief systems and norms. It would also be useful to know whether such societies are ideologically more amenable to political-institutional influence than the more heterogeneous ones.

Further research could also examine differences in the progression of disability policy design and implementation among various SSA countries, ascertaining sets of key players and their respective influence both in policy advancements and sociological ideational reforms at the local level.

\section{References}

Barker, Clare, and Stuart Murray. 2010. Disabling Postcolonialism: Global Disability Cultures and Democratic Criticism. Journal of Literary \& Cultural Disability Studies 4 (3): 219-236.

Baumgartner, Frank R., and Bryan D. Jones. 1991. Agenda Dynamics and Policy Subsystems. The Journal of Politics 53 (4): 1044-1074.

Béland, Daniel. 2010. The Idea of Power and the Role of Ideas. Political Studies Review 8 (2): 145-154.

Besley, Timothy, and Torsten Persson. 2014. Why Do Developing Countries Tax So Little? Journal of Economic Perspectives 28 (4): 99-120. 
Boli, John, and George M. Thomas, eds. 1999. Constructing World Culture: International Nongovernmental Organizations Since 1875. Stanford: Stanford University Press.

Campbell, John L. 2004. Institutional Change and Globalization. Princeton: Princeton University Press.

Carstensen, Martin B. 2011. Paradigm Man vs. the Bricoleur: Bricolage as an Alternative Vision of Agency in Ideational Change. European Political Science Review 3 (1): 147-167.

Checkel, Jeffrey T. 1997. International Norms and Domestic Politics: Bridging the Rationalist - Constructivist Divide. European Journal of International Relations 3 (4): 473-495.

- 2005. International Institutions and Socialization in Europe: Introduction and Framework. International Organization 59 (4): 801-826. Christians, Clifford G. 2004. Ubuntu and Communitarianism in Media Ethics. Ecquid Novi: African Journalism Studies 25 (2): 235-256.

Clarke, John, Dave Bainton, Noémi Lendvai, and Paul Stubbs. 2015. Making Policy Move: Towards a Politics of Translation and Assemblage. Bristol: Policy Press.

Devlieger, P.J. 1999. From Handicap to Disability: Language Use and Cultural Meaning in the United States. Disability and Rehabilitation 21 (7): 346-354. Evangelista, Matthew. 1995. The Paradox of State Strength: Transnational Relations, Domestic Structures, and Security Policy in Russia and the Soviet Union. International Organization 49 (1): 1-38. http://www.jstor.org/ stable/2706865.

Finger, Matthias, and Thomas Princen. 2013. Environmental NGOs in World Politics: Linking the Local and the Global. London: Routledge.

Grech, Shaun. 2011. Recolonising Debates or Perpetuated Coloniality? Decentring the Spaces of Disability, Development and Community in the Global South. International Journal of Inclusive Education 15 (1): 87-100.

- 2015. Disability and Poverty in the Global South: Renegotiating Development in Guatemala. Basingstoke: Palgrave Macmillan.

Gyekye, Kwame. 1997. Tradition and Modernity: Philosophical Reflections on the African Experience. Oxford: Oxford University Press.

Haang'andu, Privilege. 2018. Transnationalizing Disability Policy in Embedded Cultural-Cognitive Worldviews: The Case of Sub-Saharan Africa. Disability and the Global South 5 (1): 1292-1314. 
2019. Transnational Actors and Policy Diffusion: Ideational Pathways Towards Successful Disability Policy Diffusion in Southern Africa. Saskatoon: University of Saskatchewan (PhD Dissertation in Public Policy).

Haang'andu, Privilege, and Daniel Béland. 2019. Democratization Without Westernisation? Embedding Democracy in Local African Cultures. Politikon 46 (2): 219-239. https://doi.org/10.1080/02589346.2019.1612179.

Hall, Peter A. 1993. Policy Paradigms, Social Learning and the State: The Case of Economic Policymaking in Britain. Comparative Politics 25 (3): 275-296. Kaaba, O'Brien. 2015. The Challenges of Adjudicating Presidential Election Disputes in Africa: Exploring the Viability of Establishing an African Supranational Elections Tribunal. PhD diss., University of South Africa.

Keck, Margaret E., and Kathryn Sikkink. 1998. Historical Precursors to Modern Transnational Advocacy Networks. In Activists Beyond Borders: Advocacy Networks in International Politics, ed. Margaret E. Keck and Kathryn Sikkink, 59-66. Ithaca and London: Cornell University Press.

Kingdon, John W. 2003. Agendas, Alternatives, and Public Policies. New York: Longman.

Lukes, Steven. 2004. Power: A Radical View. 2nd ed. Basingstoke: Palgrave Macmillan.

Mauro, Paolo. 1998. Corruption and the Composition of Government Expenditure. Journal of Public Economics 69 (2): 263-279.

Meekosha, Helen. 2011. Decolonizing Disability: Thinking and Acting Globally. Disability \& Society 26 (6): 667-682.

Miljan, Lydia. 2012. Public Policy in Canada: An Introduction. Oxford: Oxford University Press.

Mji, Gubela, Siphokazi Gcaza, Leslie Swartz, Malcolm MacLachlan, and Barbara Hutton. 2011. An African Way of Networking Around Disability. Disability \& Society 26 (3): 365-368.

Morriss, Peter. 2006. Steven Lukes on the Concept of Power. Political Studies Review 4 (2): 124-135.

North, Douglass C. 1994. Economic Performance Through Time. The American Economic Review 84 (3): 359-368.

Orenstein, Mitchell A. 2008. Privatizing Pensions: The Transnational Campaign for Social Security Reform. Princeton: Princeton University Press.

Ostrom, Elinor. 2014. Collective Action and the Evolution of Social Norms. Journal of Natural Resources Policy Research 6 (4): 235-252.

Parsons, Craig. 2002. Showing Ideas as Causes: The Origins of the European Union. International Organization 56 (1): 47-84. 
University Press.

Risse, Thomas. 2007. Transnational Actors and World Politics. In Corporate Ethics and Corporate Governance, ed. Walther Ch. Zimmerli, Markus Holzinger, and Klaus Richter, 251-286. Berlin: Springer.

Scott, Richard W. 2005. Institutional Theory: Contributing to a Theoretical Research Program. In Great Minds in Management: The Process of Theory Development, ed. Ken G. Smith and Michael A. Hill, 460-485. Oxford: Oxford University Press.

Soldatic, Karen, and Shaun Grech. 2014. Transnationalising Disability Studies: Rights, Justice and Impairment. Disability Studies Quarterly 34 (2). https:// dsq-sds.org/article/view/4249.

Trebilcock, Michael J. 2014. Dealing with Losers: The Political Economy of Policy Transitions. Oxford: Oxford University Press.

Vanhala, Lisa. 2010. Making Rights a Reality? Disability Rights Activists and Legal Mobilization. Cambridge: Cambridge University Press.

Waltz, Kenneth N. 2000. Structural Realism After the Cold War. International Security 25 (1): 5-41.

Wiredu, Kwasi, ed. 2008. A Companion to African Philosophy. Oxford: John Wiley \& Sons.

Open Access This chapter is licensed under the terms of the Creative Commons Attribution 4.0 International License (http://creativecommons.org/licenses/ by/4.0/), which permits use, sharing, adaptation, distribution and reproduction in any medium or format, as long as you give appropriate credit to the original author(s) and the source, provide a link to the Creative Commons licence and indicate if changes were made.

The images or other third party material in this chapter are included in the chapter's Creative Commons licence, unless indicated otherwise in a credit line to the material. If material is not included in the chapter's Creative Commons licence and your intended use is not permitted by statutory regulation or exceeds the permitted use, you will need to obtain permission directly from the copyright holder.

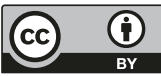

